\title{
Renal Anemia of Inflammation: The Name Is Self-Explanatory
}

\author{
Mahmut llker Yilmaz ${ }^{\mathrm{a}}$ Yalcin Solak ${ }^{\mathrm{b}}$ Adrian Covic $^{\mathrm{c}}$ David Goldsmith $^{\mathrm{d}}$ \\ Mehmet Kanbay ${ }^{\mathrm{a}}$ \\ Division of Nephrology, Department of Medicine at a Gulhane School of Medicine, Ankara, and belcuk University, \\ Meram School of Medicine, Konya, Turkey; ${ }^{C}$ Nephrology Clinic, Dialysis and Renal Transplantation Center, \\ C.I. Parhon University Hospital, Gr. T. Popa University of Medicine and Pharmacy, lasi, Romania; ${ }^{d}$ Renal Unit at \\ Guy's and St. Thomas' NHS Foundation Hospital, London, UK
}

\section{Key Words}

Anemia $\cdot$ Inflammation $\cdot$ Chronic kidney disease

\begin{abstract}
Background: Anemia is inevitable as chronic kidney disease (CKD) advances. With the advent of erythropoietin-stimulating agents (ESAs), considerable improvement has been achieved in the management of anemia. However, some patients show a reduced response to ESAs. Methods: Many factors affect the response to ESA treatment. CKD is now considered as an inflammatory disorder and this understanding led to the recognition of the central role of inflammation in ESA resistance. Inflammation is related to untoward outcomes, including atherosclerosis and anemia, in the CKD population. Furthermore, recognition of deleterious effects of proinflammatory markers at different levels of erythropoiesis led to a change in the name of 'anemia of chronic disease' to anemia of inflammation. Results: The discovery of hepcidin as the major controller of iron metabolism in anemia of inflammation answered many questions regarding the interaction of erythropoietin, iron and bone marrow. Hepcidin production in the liver is driven by three major fac-
\end{abstract}

tors: inflammation, iron overload and anemia/hypoxia. Hepcidin levels are increased in patients with CKD due to the interaction of many factors; a comprehensive understanding of these pathways is thus critical in the effort to alleviate anemia of inflammation and ESA resistance. Conclusion: In this review, we discussed the epidemiology, determinants and consequences of anemia of inflammation in CKD patients with special emphasis on the central role of hepcidin along with molecular pathways driving its production.

Copyright $\odot 2011$ S. Karger AG, Basel

\section{Introduction}

Anemia affects a substantial proportion of patients with chronic kidney disease (CKD) [1]. Renal anemia has been regarded as a special form of 'anemia of chronic disease', in which inappropriate levels of erythropoietin (EPO) are considered as the main culprit. Anemia of chronic disease, as has been known for decades, accompanies many chronic disease states, in which inflammation is frequent, such as cancer, chronic infection and autoimmune diseases [2]. Recently, the same form of

\section{KARGER \\ Fax +4161306 1234 E-Mail karger@karger.ch} www.karger.com (c) 2011 S. Karger AG, Basel 0253-5068/11/0323-0220\$38.00/0

Accessible online at: www.karger.com/bpu
Mehmet Kanbay

Alparslan Mahallesi, Umit Sokak

No. 25/14, Melikgazi

Kayseri (Turkey)

Tel. +90 50526688 66, E-Mail drkanbay@yahoo.com 
anemia has been detected in patients with acute critical illness - anemia of critical illness [3]. Therefore, the new term 'anemia of inflammation' was proposed instead of anemia of chronic disease since it better defines the underlying pathophysiology, namely the central role of inflammation. Recent molecular studies and the discovery of hepcidin have contributed to the understanding of basic pathophysiologic events that take place in the course of anemia of inflammation. Currently, CKD is largely regarded as an inflammatory condition. With the advent of erythropoiesis-stimulating agents (ESAs) in the 1990s, great improvements were achieved in the treatment of anemia, but $10 \%$ of all treated patients remained anemic despite large ESA doses, in other words those patients are resistant to ESA treatment [4]. An improved understanding of the underlying factors of hyporesponsiveness to ESA (mainly of the interaction with inflammation) may lead to a better control of anemia, possibly resulting in a decrease in the morbidity and mortality in this population. In this review, we will briefly summarize the nature, determinants and consequences of renal anemia, then focus on the role of inflammation in 'anemia of inflammation of renal disease' along with current developments in this field.

\section{Epidemiology, Causes and Consequences of Anemia in Renal Disease}

Several large-scale population studies suggest that the incidence of anemia is less than $10 \%$ in CKD stages 1 and $2,20-40 \%$ in stage $3,50-60 \%$ in stage 4 and more than $70 \%$ in end-stage renal disease (stage 5) patients $[5,6]$. These figures clearly show that anemia develops early in the course of CKD and increases in frequency while the glomerular filtration rate further declines.

The presence of anemia despite increased EPO levels in CKD actually points to the fact that peripheral resistance or hyporesponsiveness to EPO may be the true reason for the development of anemia. The administration of exogenous EPO in the form of ESAs actually may be regarded as an intervention to overcome EPO 'resistance', by simply increasing the plasma level of EPO. A number of factors have been implicated as contributors to ESA resistance, including noncompliance with the treatment, iron deficiency (functional and true), severe hyperparathyroidism, inadequate dialysis, vitamin $\mathrm{B}_{12}$ and folate deficiency, several medications, and chronic hemolysis among others [7-9]. On the other hand, persistent inflammation is increasingly being appreciated as the major cause of EPO hyporesponsiveness.

Anemia and Inflammation

\section{CKD Is an Inflammatory Disorder}

Similarly to heart failure and atherosclerosis, CKD is now considered as an inflammatory condition. Several lines of evidence have shown that a number of inflammatory biomarkers including C-reactive protein (CRP), interleukin (IL)-1, IL-6, interferon (IFN)- $\gamma$ and tumor necrosis factor (TNF)- $\alpha$ are increased in CKD [10-12]. Importantly, the presence of inflammation is related to higher mortality rates in end-stage renal disease patients compared to controls $[13,14]$. Increased inflammation may exert its deleterious effects through a number of ways, e.g. by accelerating atherosclerosis and causing anemia of inflammation.

\section{Inflammation as a Cause of Renal Anemia}

Proinflammatory cytokines simultaneously affect erythropoiesis at several levels. This manifests as anemia of inflammation and hyporesponsiveness to ESA treatment in patients with renal disease.

Certain proinflammatory cytokines may suppress erythroid progenitor cell proliferation. In their elaborately conducted study, Allen et al. [15] showed that serum from patients with both end-stage renal disease and inflammatory disease inhibited erythroid colony formation and response to EPO. This process could be reversed by the addition of antibodies directed against TNF- $\alpha$ and IFN- $\gamma$. In vivo observations have shown that administration of TNF- $\alpha$ and IL-1 causes hypoproliferative anemia via a direct effect on erythroid progenitor cells and indirect stimulation of IFN- $\gamma$ production [16]. However, some studies argued against these observations and suggested that TNF- $\alpha$ and IL-1 stimulate the growth of early progenitors (burst-forming units) while suppressing growth at later stages of erythropoiesis, namely erythroid colonyforming units [17].

Inhibition of EPO production is another mechanism by which increased inflammation affects erythropoiesis. TNF- $\alpha$ and IL-1 have been shown to inhibit EPO production [18]. Faquin et al. [19] showed that IL-1 $\alpha$, IL$1 \beta$ and TNF- $\alpha$ caused a dose-dependent inhibition of hypoxia-induced EPO production in the Hep3b cell line.

Modulation of iron metabolism appears to be the critical pathway by which inflammation drives anemia. Anemia of inflammation is characterized by decreased iron and iron-binding capacity, increased ferritin and an abundance of iron in the bone marrow [20]. This picture

Blood Purif 2011;32:220-225 
actually represents a state of iron sequestration in reticuloendothelial cells and suggests that the plasma iron levels are inadequate to support erythropoiesis [21].

\section{Central Role of Hepcidin in Renal Anemia of Inflammation}

Marked decreases in serum iron concentrations during the first few days of systemic inflammation and infection have been known for several decades [22]. However, the exact mechanisms of this decrease were largely unknown until the recent discovery of the hepcidin molecule. Hepcidin, a 25-amino-acid peptide, is produced predominantly by hepatocytes. Hepcidin affects iron homeostasis via the binding of the cell surface iron transporter ferroportin (the only known iron exporter from the cells to plasma). This then triggers phosphorylation, internalization, ubiquitinization and degradation of ferroportin in the lysosomes [23]. The consequences of ferroportin-induced downregulation are reduced iron efflux from duodenal enterocytes into the circulation (decreased iron absorption) and reduced release of iron from macrophages into the reticuloendothelial system, which clears senescent red blood cells from the circulation. The end result of these processes is hypoferremia.

Three main factors regulate hepcidin production in the liver: iron overload [24], anemia-hypoxia [25] and inflammation. In humans injected with lipopolysaccharides, hepcidin levels greatly increase within hours, followed by the development of hypoferremia [26]. Especially IL-6 is the major driving force of hepcidin production under inflammatory conditions [27]. Some recent studies shed additional light onto molecular mechanisms of regulation of hepcidin. Maes et al. [28] elaborately showed that bone morphogenic protein-2 was a major mediator of the hepcidin stimulatory activity of sera taken from patients with multiple myeloma. Pinto et al. [29] also showed that EPO mediated hepcidin expression in hepatocytes through EPO receptor signaling and reduction of $\mathrm{C} / \mathrm{EBP}-\alpha$. The unveiling of these molecular pathways is important to design targeted therapies to interrupt hepcidin expression in anemia of inflammation.

Hepcidin concentrations are increased in patients with CKD [30]. Increased inflammation seems to be responsible for this increase; however, even CKD patients without significant inflammation had elevated hepcidin levels, which progressively increase along with the decline in glomerular filtration rate $[31,32]$.

\section{Causal Role of Hepcidin in Anemia of Inflammation and Effects of EPO}

EPO hyporesponsiveness or resistance, as mentioned earlier, is a joint product of many factors [4]. On the other hand, recent accruing evidence made clear that inflammation is pivotal among these factors. Hemodialysis patients with CRP levels higher than $20 \mathrm{mg} / \mathrm{l}$ require $80 \%$ higher ESA doses than patients with lower levels of CRP [33]. The causal role of hepcidin in the process of anemia of inflammation has been supported by some observations. First, hepcidin-overexpressing transgenic mice had a blunted response to EPO [34]. Second, and more importantly, in a mouse model of anemia of inflammation induced by injections of Brucella abortus, neutralizing monoclonal antibodies to hepcidin along with ESA restored normal hemoglobin levels while ESA alone was not effective [35]. More recently, Song et al. [36] treated patients with multicentric Castleman's disease, a rare lymphoproliferative disorder accompanied by a systemic inflammatory response and anemia, with anti-IL-6 receptor antibody (tocilizumab) and found that tocilizumab treatment resulted in a rapid reduction of serum hepcidin- 25 in 5 of 6 patients. The authors conclude that IL- 6 played an essential role in the induction of hepcidin in this type of anemia.

Growing evidence suggests that administration of exogenous EPO may lead to reduced hepcidin levels, thus ameliorating anemia of inflammation and iron sequestration. A very recent study in healthy humans showed that EPO administration resulted in marked and sustained suppression of circulating hepcidin, not mediated by reduced circulating iron [37]. Marked suppression of hepcidin was observed as early as $24 \mathrm{~h}$ after EPO administration; hepcidin suppression persisted throughout the week, with incomplete recovery occurring over a 2-week period, suggesting that the effect of EPO was direct and independent of an increase in hematocrit. Another study, by Toba et al. [38], also showed that low-dose ESA normalized endothelial function, vascular inflammation and oxidative stress in rats with renal ablation beyond hematopoiesis. One can assume, as suggested by the results of this study, that decreased inflammation and oxidative stress may be an important determinant in the reduction of hepcidin levels by EPO treatment. Huang et al. [39] showed that erythropoiesis stimulated by EPO but not hypoxia, downregulates hepcidin in a dose-dependent manner, even in the presence of lipopolysaccharide or dietary iron loading, which may act additively. This experimental study also showed that erythropoietic 
Fig. 1. Main regulators of hepcidin production in CKD patients. Note complex interrelations of inflammation, EPO deficiency and hypoferremia. The figure also shows effects of ESA, parenteral iron and anti-inflammatory treatments on hepcidin and inflammation. Additionally, frequently encountered complications of CKD, including increased inflammation, anemia and hypoxia coupled with relative EPO deficiency, lead to increased serum hepcidin levels. Increased hepcidin levels in turn may cause decreased absorption of iron from the duodenum and also restricts release of iron from the macrophages with resultant hypoferremia. There occurs a blunted response to exogenous EPO administration in the presence of increased hepcidin levels. EPO treatment and iron supplementation act directly in the opposite direction to decrease serum hepcidin levels. EPO administration also indirectly decreases serum hepcidin levels by attenuating inflammation.

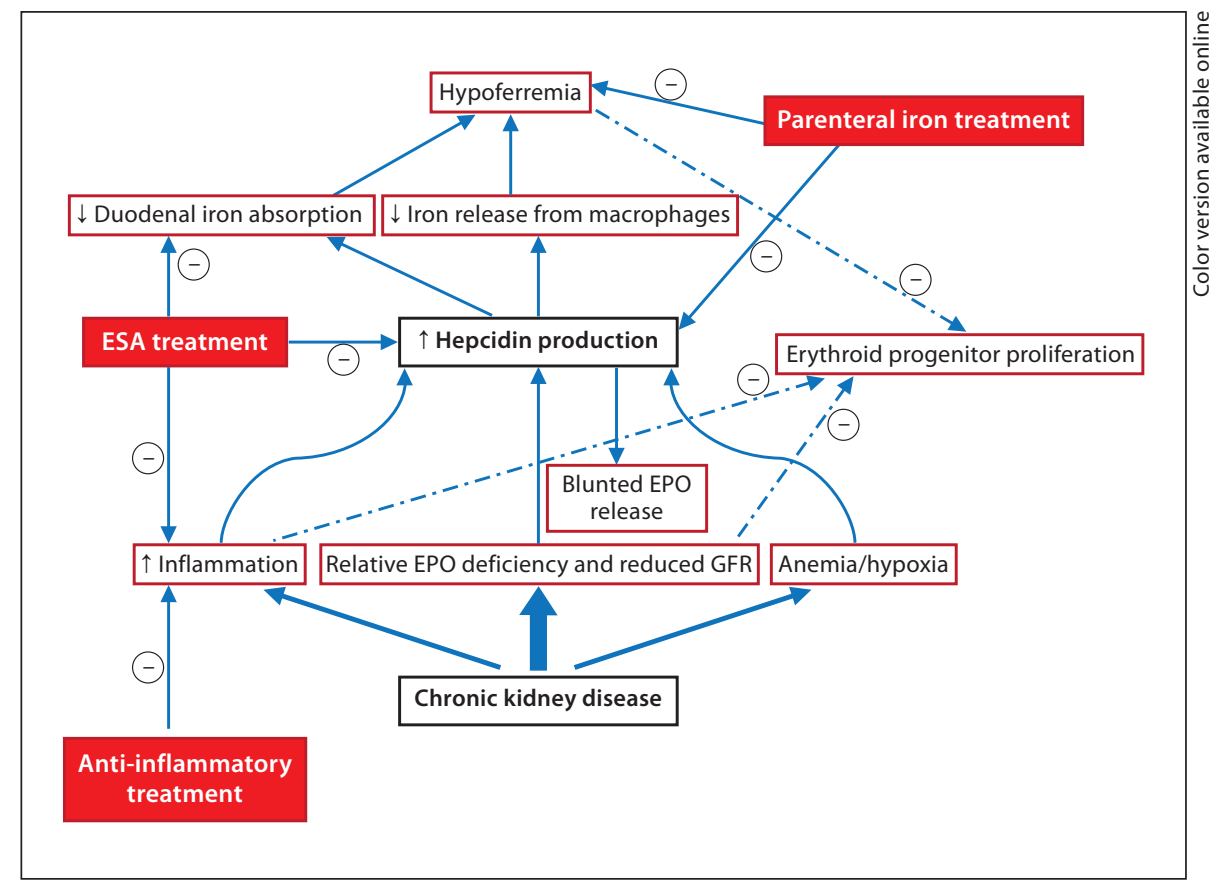

drive can inhibit both inflammatory and iron-sensing pathways, at least in part, via the suppression of STAT3 and SMAD4 signaling in vivo. Several other experimental studies also showed that EPO downregulated hepcidin, suggesting that relative EPO deficiency due to CKD may also be responsible for increased serum hepcidin levels $[29,40]$. Finally, in their recent study, Srai et al. [41] demonstrated that 4 of 5 nephrectomized rats showed significant increases in serum hepcidin levels along with significant decreases in duodenal iron absorption. Treatment of nephrectomized rats with EPO reversed these effects, resulting in a nonsignificant decrease in hepcidin expression, but a significant increase in duodenal iron transport to levels observed in the sham-operated group. One of the important findings of this study was that EPO also had effects on small-bowel cells regulating iron transport independent of hepcidin. Main factors determining the production of hepcidin and the effects of some treatment modalities, i.e. ESA, parenteral iron and anti-inflammatory treatment, on this pathway are shown in figure 1.

Some studies have demonstrated the ability of exogenously administered EPO to suppress the levels of inflammatory biomarkers, including IL-6, IL- 8 and TNF- $\alpha$ $[32,42,43]$. This decrease in the levels of the proinflammatory cytokines, particularly IL-6, may explain the decreases in hepcidin levels observed in EPO-treated sub- jects. Pavese et al. [44] demonstrated that, in ESA-hyporesponsive cancer patients, high baseline serum levels of TNF- $\alpha$ and IL- 6 were significantly correlated with a negative response to ESA. This may be attributed to the fact that profound and persistent inflammation, which may not be overcome by ESA administration, may decrease hepcidin levels and account for the reduced response to ESA treatment.

\section{Potential Improvements in Anemia of Inflammation and EPO Hyporesponsiveness through Treatment of Inflammation}

EPO resistance can be overcome by simply increasing doses of ESA in the majority of the cases. However, in many patients, high doses of ESA do not suffice and such high doses are now questioned with respect to adverse effects [45]. Severe inflammation may blunt EPO response both in terms of anemia and levels of inflammatory biomarkers. Hence, in patients with profound and persistent inflammation, amelioration of inflammatory states by means of various treatment modalities may be helpful in attaining optimal responses to ESA treatment. In a recent study, Ferrari et al. [46] showed that pentoxifylline reduced circulating IL- 6 and improved hemoglobin in noninflammatory stage -4 to -5 CKD patients. These changes 
were associated with changes in circulating transferrin saturation and ferritin, suggesting improved iron release. The authors hypothesized that pentoxifylline improves iron disposition, possibly through modulation of hepcidin. An ongoing multicenter study has been designed to determine the effect of oxpentifylline in EPO-resistant anemia [47].

Treatment with statins is well established for its beneficial effects on inflammation [48, 49]. Sirken et al. [50] analyzed the effect of statin therapy on ESA requirements in 38 hemodialysis patients in a single-center retrospective study. The requirements in erythropoiesis-stimulating agents decreased by $25 \%$ in the statin-treated group. These beneficial effects of statins on anemia may be mediated through decreased proinflammatory cytokines and CRP levels as well as decreased serum levels of hepcidin. This latter possibility has recently been investigated. In an 8-week study conducted on maintenance hemodialysis patients, $80 \mathrm{mg}$ /day fluvastatin treatment significantly decreased total cholesterol, LDL cholesterol, hs-CRP and serum prohepcidin levels [51]. In an 8-week trial of $20 \mathrm{mg} /$ day simvastatin in hemodialysis patients, $\mathrm{Li}$ et al. [52] found that baseline serum prohepcidin levels were significantly higher in hemodialysis patients compared to normal controls. However, simvastatin did not significantly change the serum prohepcidin, hs-CRP, or IL- 6 concentrations in maintenance hemodialysis patients despite significant improvements in lipid profiles.
This lack of effect on inflammatory biomarkers and serum prohepcidin levels may just be due to the lower dose of statins used. Further studies are obviously needed to better delineate the effects of statins in this regard.

In conclusion, recent years have ushered a new era in understanding of anemia of chronic disease. Increased awareness of the central role of inflammation led to a change in the nomenclature of anemia of chronic illness. Patients with CKD constitute a considerable portion of these anemic patients since both inflammation and relative EPO deficiency are prevalent in this population. Despite progress in the management of anemia with the advent of recombinant human EPO, some patients show a blunted response to these agents. There is still controversy about optimal hemoglobin targets in CKD patients because deleterious results were obtained in large randomized trials aiming at hemoglobin levels above $13 \mathrm{~g} / \mathrm{dl}$. There is still concern regarding potentially harmful results of high-dose ESAs. The discovery of hepcidin is a landmark development in anemia of inflammation. Increasing understanding of the effects of this peptide will hopefully lead to development of drugs aiming at several points in this molecular pathway. Maybe alleviation of inflammation with other means coupled with targeted therapies of hepcidin antagonism will eventually enable us to overcome resistance to EPO and thus avoid the harmful effects of high doses.

\section{References}

1 Voormolen N, Grootendorst DC, Urlings TA, Boeschoten EW, Sijpkens YW, Huisman RM, et al: Prevalence of anemia and its impact on mortality and hospitalization rate in predialysis patients. Nephron Clin Pract 2010;115:c133-c141.

2 Zarychanski R, Houston DS: Anemia of chronic disease: a harmful disorder or an adaptive, beneficial response? CMAJ 2008; 179:333-337.

3 Asare K: Anemia of critical illness. Pharmacotherapy 2008;28:1267-1282.

4 Kanbay M, Perazella MA, Kasapoglu B, Koroglu M, Covic A: Erythropoiesis stimulatory agent-resistant anemia in dialysis patients: review of causes and management. Blood Purif 2010;29:1-12.

5 Hsu CY, McCulloch CE, Curhan GC: Epidemiology of anemia associated with chronic renal insufficiency among adults in the United States: results from the Third $\mathrm{Na}$ tional Health and Nutrition Examination Survey. J Am Soc Nephrol 2002;13:504-510.
-6 Astor BC, Muntner P, Levin A, Eustace JA, Coresh J: Association of kidney function with anemia: the Third National Health and Nutrition Examination Survey (1988-1994). Arch Intern Med 2002;162:1401-1408.

7 Lacombe C: Resistance to erythropoietin. N Engl J Med 1996;334:660-662.

8 Rao DS, Shih MS, Mohini R: Effect of serum parathyroid hormone and bone marrow fibrosis on the response to erythropoietin in uremia. N Engl J Med 1993;328:171-175.

-9 Ono K, Hisasue Y: Is folate supplementation necessary in hemodialysis patients on erythropoietin therapy. Clin Nephrol 1992;38: 290-292.

10 Stenvinkel P: Inflammatory and atherosclerotic interactions in the depleted uremic patient. Blood Purif 2001;19:53-61.

11 Bergstrom J, Lindholm B, Lacson E Jr, Owen W Jr, Lowrie EG, Glassock RJ, et al: What are the causes and consequences of the chronic inflammatory state in chronic dialysis patients? Semin Dial 2000;13:163-175.
12 Stenvinkel P, Barany P, Heimburger O, Pecoits-Filho R, Lindholm B: Mortality, malnutrition, and atherosclerosis in ESRD: what is the role of interleukin-6? Kidney Int Suppl 2002;80:103-108.

13 Kalantar-Zadeh K, Brennan ML, Hazen SL: Serum myeloperoxidase and mortality in maintenance hemodialysis patients. Am J Kidney Dis 2006;48:59-68.

14 Qureshi AR, Alvestrand A, Divino-Filho JC, Gutierrez A, Heimburger O, Lindholm B, et al: Inflammation, malnutrition, and cardiac disease as predictors of mortality in hemodialysis patients. J Am Soc Nephrol 2002; 13(suppl 1):S28-S36.

15 Allen DA, Breen C, Yaqoob MM, Macdougall IC: Inhibition of CFU-E colony formation in uremic patients with inflammatory disease: role of IFN- $\gamma$ and TNF- $\alpha$. J Investig Med 1999;47:204-211. 
16 Goicoechea M, Martin J, de Sequera P, Quiroga JA, Ortiz A, Carreno V, et al: Role of cytokines in the response to erythropoietin in hemodialysis patients. Kidney Int 1998; 54:1337-1343.

-17 Trey JE, Kushner I: The acute phase response and the hematopoietic system: the role of cytokines. Crit Rev Oncol Hematol 1995;21:118.

18 Jelkmann W: Proinflammatory cytokines lowering erythropoietin production. J Interferon Cytokine Res 1998;18:555-559.

-19 Faquin WC, Schneider TJ, Goldberg MA: Effect of inflammatory cytokines on hypoxiainduced erythropoietin production. Blood 1992;79:1987-1994.

20 de Francisco AL, Stenvinkel P, Vaulont S: Inflammation and its impact on anaemia in chronic kidney disease: from haemoglobin variability to hyporesponsiveness. NDT Plus 2009;2(suppl_1):i18-i26.

21 Ganz T: Iron in innate immunity: starve the invaders. Curr Opin Immunol 2009;21:6367.

-22 Cartwright GE, Lauritsen MA, Humphreys S, Jones PJ, Merrill IM, Wintrobe MM: The anemia of infection. II. The experimental production of hypoferremia and anemia in dogs. J Clin Invest 1946;25:81-86.

$\checkmark 23$ De Domenico I, Ward DM, Langelier C, Vaughn MB, Nemeth E, Sundquist WI, et al: The molecular mechanism of hepcidinmediated ferroportin down-regulation. Mol Biol Cell 2007;18:2569-2578.

-24 Jenkins ZA, Hagar W, Bowlus CL, Johansson HE, Harmatz P, Vichinsky EP, et al: Iron homeostasis during transfusional iron overload in $\beta$-thalassemia and sickle cell disease: changes in iron regulatory protein, hepcidin, and ferritin expression. Pediatr Hematol Oncol 2007;24:237-243.

-25 Nicolas G, Chauvet C, Viatte L, Danan JL, Bigard X, Devaux I, et al: The gene encoding the iron regulatory peptide hepcidin is regulated by anemia, hypoxia, and inflammation. J Clin Invest 2002;110:1037-1044.

-26 Kemna E, Pickkers P, Nemeth E, van der Hoeven H, Swinkels D: Time-course analysis of hepcidin, serum iron, and plasma cytokine levels in humans injected with LPS. Blood 2005;106:1864-1866.

-27 Nemeth E, Rivera S, Gabayan V, Keller C, Taudorf S, Pedersen BK, et al: IL-6 mediates hypoferremia of inflammation by inducing the synthesis of the iron regulatory hormone hepcidin. J Clin Invest 2004;113:1271-1276.

-28 Maes K, Nemeth E, Roodman GD, Huston A, Esteve F, Freytes C, et al: In anemia of multiple myeloma, hepcidin is induced by increased bone morphogenetic protein 2 . Blood 2010;116:3635-3644.
29 Pinto JP, Ribeiro S, Pontes H, Thowfeequ S, Tosh D, Carvalho F, et al: Erythropoietin mediates hepcidin expression in hepatocytes through EPOR signaling and regulation of C/EBP $\alpha$. Blood 2008;111:5727-5733.

30 Li H, Rose MJ, Tran L, Zhang J, Miranda LP, James CA, et al: Development of a method for the sensitive and quantitative determination of hepcidin in human serum using LCMS/MS. J Pharmacol Toxicol Methods 2009; 59:171-180.

-31 Zaritsky J, Young B, Wang HJ, Westerman M, Olbina G, Nemeth E, et al: Hepcidin - a potential novel biomarker for iron status in chronic kidney disease. Clin J Am Soc Nephrol 2009;4:1051-1056.

32 Ashby DR, Gale DP, Busbridge M, Murphy KG, Duncan ND, Cairns TD, et al: Plasma hepcidin levels are elevated but responsive to erythropoietin therapy in renal disease. Kidney Int 2009;75:976-981.

33 Barany P: Inflammation, serum C-reactive protein, and erythropoietin resistance. Nephrol Dial Transplant 2001;16:224-227.

34 Roy CN, Mak HH, Akpan I, Losyev G, Zurakowski D, Andrews NC: Hepcidin antimicrobial peptide transgenic mice exhibit features of the anemia of inflammation. Blood 2007;109:4038-4044.

35 Sasu BJ HM: Boone TC inventor Amgen Inc. Thousand Oaks, Calif assignee. Hepcidin, hepcidin antagonists and methods of use. USA patent US2008213277. September 2008.

36 Song SN, Tomosugi N, Kawabata H, Ishikawa T, Nishikawa T, Yoshizaki K: Down-regulation of hepcidin resulting from long-term treatment with an anti-IL-6 receptor antibody (tocilizumab) improves anemia of inflammation in multicentric Castleman's disease (MCD). Blood 2010;116;3627-3634.

37 Ashby DR, Gale DP, Busbridge M, Murphy KG, Duncan ND, Cairns TD, et al: Erythropoietin administration in humans causes a marked and prolonged reduction in circulating hepcidin. Haematologica 2010;95:505508.

38 Toba H, Nakashima K, Oshima Y, Kojima Y, Tojo C, Nakano A, et al: Erythropoietin prevents vascular inflammation and oxidative stress in subtotal nephrectomized rat aorta beyond hematopoiesis. Clin Exp Pharmacol Physiol 2010;37:1139-1146.

39 Huang H, Constante M, Layoun A, Santos MM: Contribution of STAT3 and SMAD4 pathways to the regulation of hepcidin by opposing stimuli. Blood 2009;113:3593-3599.

40 Kong WN, Chang YZ, Wang SM, Zhai XL, Shang JX, Li LX, et al: Effect of erythropoietin on hepcidin, DMT1 with IRE, and hephaestin gene expression in duodenum of rats. J Gastroenterol 2008;43:136-143.
41 Srai SK, Chung B, Marks J, Pourvali K, Solanky N, Rapisarda C, et al: Erythropoietin regulates intestinal iron absorption in a rat model of chronic renal failure. Kidney Int 2010;78:660-667.

42 Shen Y, Wang Y, Li D, Wang C, Xu B, Dong $\mathrm{G}$, et al: Recombinant human erythropoietin pretreatment attenuates heart ischemia-reperfusion injury in rats by suppressing the systemic inflammatory response. Transplant Proc 2010;42:1595-1597.

43 Bian XX, Yuan XS, Qi CP: Effect of recombinant human erythropoietin on serum S100B protein and interleukin-6 levels after traumatic brain injury in the rat. Neurol Med Chir (Tokyo) 2010;50:361-366.

44 Pavese I, Satta F, Todi F, Di Palma M, Piergrossi P, Migliore A, et al: High serum levels of TNF- $\alpha$ and IL- 6 predict the clinical outcome of treatment with human recombinant erythropoietin in anaemic cancer patients. Ann Oncol 2010;21:1523-1528.

45 Singh AK: What is causing the mortality in treating the anemia of chronic kidney disease: erythropoietin dose or hemoglobin level? Curr Opin Nephrol Hypertens 2010;19: 420-424.

46 Ferrari P, Mallon D, Trinder D, Olynyk JK: Pentoxifylline improves haemoglobin and interleukin- 6 levels in chronic kidney disease. Nephrology (Carlton) 2010;15:344349.

47 Johnson DW, Hawley CM, Rosser B, Beller E, Thompson C, Fassett RG, et al: Oxpentifylline versus placebo in the treatment of erythropoietin-resistant anaemia: a randomized controlled trial. BMC Nephrol 2008;9:8.

48 Morgan C, Zappitelli M, Gill P: Statin prophylaxis and inflammatory mediators following cardiopulmonary bypass: a systematic review. Crit Care 2009;13:R165.

-49 Horiuchi Y, Hirayama S, Soda S, Seino U, Kon M, Ueno T, et al: Statin therapy reduces inflammatory markers in hypercholesterolemic patients with high baseline levels. J Atheroscler Thromb 2010;17:722-729.

50 Sirken G, Kung SC, Raja R: Decreased erythropoietin requirements in maintenance hemodialysis patients with statin therapy. ASAIO J 2003;49:422-425

51 Arabul M, Gullulu M, Yilmaz Y, Akdag I, Kahvecioglu S, Eren MA, et al: Effect of fluvastatin on serum prohepcidin levels in patients with end-stage renal disease. Clin Biochem 2008;41:1055-1058.

52 Li XY, Chang JP, Su ZW, Li JH, Peng BS, Zhu SL, et al: How does short-term low-dose simvastatin influence serum prohepcidin levels in patients with end-stage renal disease? A pilot study. Ther Apher Dial 2010;14:308314 . 